\title{
PROSPECTS
}

\section{From geek to chic}

\section{Many stereotypes should be crushed, but some can prove beneficial to a fledgling scientist, says Peter Fiske.}

In November, President Barack Obama held a news conference to announce a new national science fair. "Scientists and engineers ought to stand side by side with athletes and entertainers as role models, and here at the White House, we're going to lead by example," he said. "We're going to show young people how cool science can be."

The thought that scientists and engineers could one day be elevated in social stature to the level of pop-culture icons is a tantalizing prospect. Of course, one has only to turn on the television or watch any number of movies to see how society really imagines them. Although the mainstream media might at times portray scientists as powerful and villainous, $\mathrm{a} \mathrm{PhD}$ at the end of a name tends to conjure up images of pallor and social awkwardness - people more to be pitied than feared. In his book Mad, Bad and Dangerous? The Scientist and the Cinema (Reaktion Books, 2005), Christopher Frayling notes that surveys of attitudes over the past 50 years have shown that the cultural stereotype surrounding 'scientist' has been largely consistent - and negative.

It is easy for scientists and engineers to resign themselves to some degree of social stigmatization or even to embrace an in-yourface uber-geek image as a badge of honour. Brisk sales of Garth Sundem's book The Geeks' Guide to World Domination: Be Afraid, Beautiful People (Three Rivers Press, 2009) imply the notion has broad appeal. But the bizarre image that science degrees can conjure in some people's minds affects more than just dating prospects: how people perceive scientists and engineers affects what they think people in these professions can do and, ultimately, what their value is to society. It certainly affects the range of career options available to them.

Perhaps, by unpacking the cultural stereotypes that surround 'scientist' or 'PhD', scientists will be able to understand how some stereotypes work against them - and that may actually work to their advantage. This can be useful for young scientists who hope to advance, especially those whose non-traditional career paths involve frequent interactions with non-science professionals.

\section{Judging a book by its cover}

The physical stereotype of the scientist (male or female) is hardly flattering. Comically unkempt, poorly dressed, wearing any number of geek accoutrements (pocket protector, slide rule, calculator), the stereotypical scientist is out of touch with his or her surroundings, and compulsively obsessed with the science.

This stereotype is the easiest to address. From my attendance at many science meetings

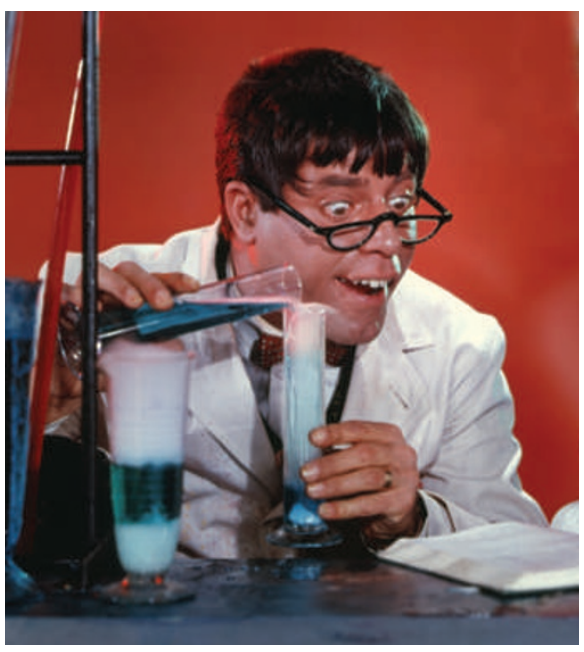

and my business dealings with scientists in academia, government and the private sector, people with $\mathrm{PhDs}$ seem to be indistinguishable from the population at large when they are not wearing a lab coat. It is true that many research work environments have few if any dress codes, and attire, especially in graduate school, can become quite casual. But often it is not social ineptitude that prevents young scientists from dressing better; it is poverty.

Still, young scientists sometimes fail to appreciate how their attire can limit their opportunities outside the lab. Fortunately, the rules of business dress and etiquette are much easier to master than the topics they encounter in graduate school. Polishing their appearance at conferences or when interacting with visitors can help young scientists to be taken seriously. Who knows? Potential contacts may even mistake graduate students for faculty members.

Scientists and engineers face more serious prejudices, especially in the business world. Many business managers fear that $\mathrm{PhDs}$ are simple-minded about money, impractical about time, have no sense of deadlines and are uncompromisingly idealistic. Where do these stereotypes come from? To be fair, obtaining a PhD does demand an intensity of study and a single-mindedness of focus, even a degree of obsessive compulsion. This may be helpful for a research career that focuses on a single topic. But in most other work environments, employers are looking for people who are leaders, not hermits; team players, not arrogant loners. In a job interview, scientists should be sure to work in stories about how they worked successfully in teams, have led activities and enjoy working with others.

Perhaps the most self-limiting stereotype about PhD scientists and what they are capable of comes from the scientists themselves. After spending so many years obtaining an advanced degree in a particular field of study, scientists understandably value their technical skills the most. And, having become so highly qualified in one field, they often feel totally unqualified to address issues that may exist in other fields or industries. When scientists look for employment they naturally frame every opportunity in terms of their field of study and their expertise: chemists look for jobs labelled chemist, biologists look for jobs labelled biologist.

\section{The bigger picture}

In truth, the training to become a scientist or an engineer comes with a long list of transferable skills that are of enormous value in the 'outside world'. Communication skills, analytical skills, independence, problemsolving skills, learning ability - these are all valuable. But scientists and engineers tend to discount these things because they are basic requirements of their profession. They tend to think of themselves as subject-matter experts rather than as broadly adaptable problem solvers. Unfortunately, the world needs a lot more of the latter than the former.

These more serious stereotypes deserve attention as scientists focus on advancing their careers. In networking opportunities, and especially during job interviews outside academia, it is particularly important to address the potential negative stereotypes that the wider world may harbour about a PhD. Instead of focusing the discussion on science and technical abilities, scientists should educate people about the leadership roles they have had, or the broad range of roles that they fulfil in the lab, or their interest in contributing to a bigger goal than just their own research.

A different sort of pervasive stereotype may prove much more beneficial - the scientist or engineer as a genius. Cartoons of the stereotypical science geek often show a thought bubble filled with equations and formulae hovering over their heads. People see a PhD after a name, and they assume that the person is a genius - a rocket scientist, even a reincarnation of Einstein himself.

This can be a good thing. By addressing the negative stereotypes, then dispelling them, scientists will leave their audience with the 'scientist as genius' label. As they strive to advance their careers, scientists should try not to dispel that misconception. This is one stereotype, after all, that fledgling scientists can use to great advantage.

Peter Fiske is chief technology officer of PAX Water Technologies in San Rafael, California, and author of Put Your Science to WORK. 